\title{
Recent trends in the development of electrochemical glucose biosensors
}

\begin{abstract}
Glucose sensing is of great significance as diabetes is becoming one of the biggest health care challenges of the near future. Substantial effort has been made to design and develop novel glucose monitoring devices. The aim of this review is to provide a brief overview of the recent trends in the development of glucose biosensors based on electrochemical detection procedure. A brief introduction to glucose biosensor is presented, with attention given to the challenges in non-enzymatic and enzymatic electrochemical glucose biosensors. Special emphasis is given to discussion on biocompatible conducting polymer and its derivatives used in the fabrication of electrochemical glucose biosensors.
\end{abstract}

Volume 3 Issue I - 2017

\author{
Gul Rahman,' Shabeer Ahmad Mian² \\ 'University of Peshawar, Pakistan \\ ${ }^{2}$ Department of Physics, University of Peshawar, Pakistan
}

Correspondence: Gul Rahman, Institute of Chemical Sciences, University of Peshawar, 25I20, Peshawar, Pakistan,

Email gul_rahman47@uop.edu.pk

Received: May 19, 2017 | Published: August 29, 2017

Keywords: glucose, biosensor, electrochemical, enzymatic, non-enzymatic

Abbreviations: PANI, polyaninline; GOx, glucose oxidase; SWCNH, single-walled carbon nanohorns

\section{Introduction}

The research interest behind the development of glucose monitoring systems is in fact firmly related to diabetes mellitus, a group of endocrine disorders marked by abnormal levels of glucose in the blood. ${ }^{1,2}$ World Health Organization (WHO) has recently reported about 422 million people around the globe suffered from this disease. ${ }^{3}$ Diabetes is categorized mainly into two types. In type 1 , the immune system wrongly identifies and attacks pancreatic beta cells that are responsible for insulin production. As a result, not enough insulin is produced by the pancreas. In case of type 2, human body become insensitive to insulin due to persistent overexposure to glucose ${ }^{4}$ Regardless of the cause of diseases, both types are equally contributing to the complications such as kidney failure, blindness, cardiovascular disease, non healing of wounds, and neurological disorders. ${ }^{4,5}$ Therefore, maintaining the level of glucose in human blood is of great clinical importance, and accordingly the glucose biosensors industry is growing rapidly. In the last 30 years, a lot of struggles have been made to develop sensitive and selective glucose biosensors. ${ }^{6}$ For the detection of glucose, two methods namely optical and electrochemical have been used. In optical methods, photons are measured which do not require wire connection, thereby making them very useful for bioimaging and in vivo biosensing. These methods include absorptiometry, reflectometry, surface plasmon resonance and fluorescence. ${ }^{7,8}$ Electrochemical methods, especially amperometric methods, have been extensively employed in glucose sensing because of its promising characteristics such as rapid response, high sensitivity, and convenient operation. ${ }^{9}$

\section{Discussion}

There are two categories of glucose sensors i.e., enzymatic and nonenzymatic. The conventional enzymatic glucose sensors involve the use of glucose oxidase (GOx), where GOx catalyzes the oxidation of glucose in the presence of $\mathrm{O}_{2}$ to produce hydrogen peroxide. During this reaction, two electrons and protons are exchanged. The reaction with glucose oxidase enzyme is shown in the following equation:

\section{GOx}

Glucose $+\mathrm{O}_{2} \rightarrow$ Gluconolactone $+\mathrm{H}_{2} \mathrm{O}_{2}$

Glucose concentration is determined by monitoring either the consumption of $\mathrm{O}_{2}$ or the generation of $\mathrm{H}_{2} \mathrm{O}_{2}$ during this process. Oxygen measurement is usually limited by the error associated to dissolved oxygen. When there is oxygen deficiency in the body fluid, this method cannot be used. On the other hand, the amount of $\mathrm{H}_{2} \mathrm{O}_{2}$ produced is usually determined by amperometric method by oxidation at the working electrode. This method however utilizes high anodic potential which results in electroactive interference, thus affecting the response signals. Non-enzymatic glucose sensing is a direct approach of monitoring glucose level based on the oxidation or reduction of glucose without using enzymes. This method is rapid and costeffective. Usually noble metals such as Pt and Au and their composites have been utilized to fabricate non-enzymatic biosensors. ${ }^{10,11}$ However, direction electrooxidation of glucose on noble metals leads to a number of issues such as sluggish glucose oxidation kinetics, poisoning of the electrodes due to adsorbed intermediate species and poor selectivity. ${ }^{12}$ Apart from $\mathrm{Pt}$ and $\mathrm{Au}$, other materials such as graphene and carbon nanotubes have also been tested as electrode material for the development of non-enzymatic glucose biosensors ${ }^{13,14}$ (Table 1).

To improve the performance of glucose biosensors, efforts have been made to search out new materials with enhanced electrical and surface properties. Conducting polymers present unique class of materials with intriguing properties such as high electrical conductivity, low energy optical transitions, high election affinity, and low ionization potential. Because of these properties, they are considered as promising materials for the development of glucose biosensors. ${ }^{27,28}$ Various conducting polymers have been studied, including polypyrrole, polythiophene, polyacetylene, and PANI. ${ }^{29}$ In glucose biosensor, the function of these polymers is to provide a matrix for enzyme immobilization and facilitate the electron transfer in enzymatic or redox reaction. Among the conducting polymers, PANI has got recent attention due to its interesting characteristics such as high conductivity, good opto-electronic properties, environmental and electrochemical stability, biocompatibility, low cost, and easy doping de-doping chemistry. ${ }^{30}$ 
Table I PANI and its composites for electrochemical glucose sensing

\begin{tabular}{|c|c|c|c|c|c|}
\hline Electrode & $\begin{array}{l}\text { Enzyme } \\
\text { immobilization }\end{array}$ & Selectivity & $\begin{array}{l}\text { Detection } \\
\text { range }\end{array}$ & Detection & Reference \\
\hline GOx/PANI & $\begin{array}{l}\text { Entrapment of GOx in } \\
\text { PANI matrix }\end{array}$ & Permeable to oxygen & $0-5 \mathrm{mM}$ & Oxygen & 15 \\
\hline GOx/poly(p-phenylenediamine) & Entrapment & $\begin{array}{l}\text { Interfering species such as } \\
\text { Lactose, sucrose, urea }\end{array}$ & $1-6 \mathrm{mM}$ & Hydrogen peroxide & 16 \\
\hline GOx/Poly-2-aminoaniline & Covalent & $\begin{array}{l}\text { Interference from ascorbic } \\
\text { acid }\end{array}$ & $0.2-20 \mathrm{mM}$ & Amperometry & 17 \\
\hline GOx/PANI/polyisoprene & Entrapment & Limit ascorbic acid & $0.01-12 \mathrm{mM}$ & Hydrogen peroxide & 18 \\
\hline Nafion/GOx/AuNPs/PANI & Cross-linking & $\begin{array}{l}\text { Negligible interference from } \\
\text { ascorbic acid }\end{array}$ & $0.00 \mathrm{I}-0.8 \mathrm{Mm} / \mathrm{L}$ & Hydrogen peroxide & 19 \\
\hline GOx-PANI nanofibers & Covalent & $\begin{array}{l}\text { No effect on the response } \\
\text { with addition of ascorbic } \\
\text { acid, uric acid and } \\
\text { 4-acetamidophenol }\end{array}$ & $0.01-1 \mathrm{mM}$ & $\begin{array}{l}\text { Direct } \\
\text { electrochemistry }\end{array}$ & 20 \\
\hline GOx-PANI nanotubes & Entrapment & $\begin{array}{l}\text { No effect on the response } \\
\text { with addition of ascorbic } \\
\text { acid, uric acid and } \\
\text { 4-acetamidophenol }\end{array}$ & $0.01-5 \mathrm{mM}$ & $\begin{array}{l}\text { Direct } \\
\text { electrochemistry }\end{array}$ & 21 \\
\hline $\begin{array}{l}\text { GOx/dendrimer-encapsulated Pt } \\
\text { nanoparticles/PANI/CNT }\end{array}$ & Cross-linking & $\begin{array}{l}\text { Effective screening of } \\
\text { uric acid, acetaminophen, } \\
\text { ascorbic acid }\end{array}$ & $0.00 \mathrm{I}-12 \mathrm{mM}$ & Hydrogen peroxide & 22 \\
\hline GOx/PtNPs/MWCNT-PANI & Covalent and adsorption & Any interferences & $0.003-8.2 \mathrm{mM}$ & Amperometry & 23 \\
\hline GOx/AuNPs/PANI nanowires & Covalent & Any interferneces & $0.00 \mathrm{I}-20 \mathrm{mM}$ & Amperometry & 24 \\
\hline $\mathrm{GO} / \mathrm{TiO}_{2} / \mathrm{PANI} / \mathrm{GC}$ & Cross-linking & $\begin{array}{l}\text { Negligible effect with } \\
\text { addition of uric acid, } \\
\text { ascorbic acid, and L-cysteine }\end{array}$ & $0.02-6 \mathrm{mM}$ & Direct electrocatalysis & 25 \\
\hline GOx/PANI- $\mathrm{TiO}_{2}$ nanotubes & Immobilization via Nafion & $\begin{array}{l}\text { Efficient elimination of } \\
\text { interferences of uric } \\
\text { acid, ascorbic acid, and } \\
\text { acetaminophen }\end{array}$ & $0.0 \mathrm{I}-2.5 \mathrm{mM}$ & $\begin{array}{l}\text { Direct } \\
\text { electrochemistry }\end{array}$ & 26 \\
\hline
\end{tabular}

Shinohara et al. reported for the first time the use of PANI as a matrix for the immobilization of GOx in the fabrication of electrochemical biosensor. ${ }^{15}$ The quantity of glucose was determined by measuring the decrease in oxygen concentration due to the enzymatic reaction. Two approaches have been adapted for the GOx attachment to polyaniline. One, GOx is introduced during the synthesis of PANI which resulted the entrapping of GOx in the matrix of polymer. This method is simple and cost effective however leads to the inactivation of enzyme. Second approach accounts for the synthesis of PANI, followed by enzyme immobilization. With this, the reactivity of enzyme could be retained but the stability is affected, particularly when the size of the polymer particle is less than the enzyme molecule and enzyme just adsorb on the polymer surface. To increase the stability, Pan et al. introduced the template assisted immobilization of GOx on PANI. Their results showed good stability and improved glucose sensing performance of the designed sensor. ${ }^{31}$ In addition, PANI derivatives such as poly(pphenylenediamine) and poly(o-amino benzoic acid)have been used for the construction of glucose biosensors. ${ }^{32,33}$ However, low stability and interference from cooxidizable substances such as ascorbic acid, uric acid etc., were the main bottlenecks in these systems.

In addition, PANI composites have been widely investigated for the design and development of glucose sensing devices. Polyanilinebenzoquinone and GOx-poly(o-aminobenzoic acid) mediated with tetrathiafulvalene and ferrocene carboxylic acid were employed for glucose sensing. ${ }^{33,34}$ The resultant structures showed better charge transport properties and overall enhanced glucose sensing performance. Hybrid structures of PANI and other materials such as carbon nanotubes (MWCNTs-PANI), Au nanoparticles (AuNPs/PANI), and Pt nanoparticles (PtNPs-PANI) have shown excellent performance with high stability, rapid response, and high selectivity. ${ }^{35-37}$ Besides, nanostructured PANI such as nanofibers, nanotubes, nanojunctions, and nanofibers have been tested for improving the performance of PANI-based glucose biosensors. ${ }^{20,21,28}$ They can be used as suitable matrix for enzyme immobilization and overall the development of stable and reliable glucose biosensors.

Moreover, carbon based-conducting materials such as graphene and carbon nanotubes have been largely exploited for glucose detection owing to their intriguing electrochemical and electrical properties. For instance, Hossain et al. ${ }^{38}$ combined glucose-treated graphene oxideactivated carbon (GRGO/AC) with Pt nanoparticle (PtNP)-glucose oxidase chitosan (Chit-GOx) and utilized it for glucose detection. The electrode exhibited a broad linear range from $0.002-10 \mathrm{mmol} / \mathrm{L}$ in urine sample. Other systems such as graphene/copper oxide nanocomposite,${ }^{39}$ direct laser engraved graphene (DLEG) with pulse deposited copper nanotubes $(\mathrm{CuNCs}),{ }^{40}$ zinc oxide $(\mathrm{ZnO})$ nanorods on chemically reduced graphene $(\mathrm{CRG}),{ }^{41}$ nickel oxide decorated 
graphene nanosheets (NiO/GNS) ${ }^{42}$ and copper nanowire decorated reduced graphene oxide $(\mathrm{CuNWs} / \mathrm{rGO})^{43}$ have been reported for electrochemical glucose sensing. Similarly, Single-walled carbon nanotubes (SWCNTs) and multi-walled carbon nanotubes (MWCNTs) in its composite form have shown promising results in the detection of glucose as summarized in Table 2. Particularly, the sensor prepared by decorating silver nanoparticles on organic functionalized MWCNT glucose detection limit of as low as $0.03 \mu \mathrm{M}$ and a linear dynamic range of 1.3 to $1000 \mu \mathrm{M} .^{47}$

Table 2 Graphene and carbon nanotubes based materials for glucose biosensors

\begin{tabular}{|c|c|c|c|c|}
\hline Electrode composition & Sensitivity/ $\mu \mathrm{A} \mathrm{mM}^{-1} \mathrm{~cm}^{-2}$ & Linear range/mM & Limit of detection/ $\mu \mathrm{M}$ & Reference \\
\hline PtNP/GRGO-Chit-GOx & 61.06 & $0.002-10$ & 2 & 38 \\
\hline $\mathrm{CuO}$ /graphene & 1065 & $0.00 \mathrm{I}-8$ & I & 39 \\
\hline CuNCs/DLEG & 4532.2 & $0.025-4$ & 0.25 & 40 \\
\hline $\mathrm{ZnO} / \mathrm{CRG}$ & 17.64 & $0.2-1.6$ & NA & 41 \\
\hline $\mathrm{NiO} / \mathrm{GNS}$ & NA & $0.005-4.2$ & 5 & 42 \\
\hline CuNWs/rGO & 1625 & Up to IImM & 0.2 & 43 \\
\hline Polyelectrolyte-SWCNTs & 157 & $0.5-5$ & 5 & 44 \\
\hline Nafion-SWCNH & 15 & $0-6$ & 6 & 45 \\
\hline MWCNTs-Chit nanowires & $5.03 \mu \mathrm{A} \mathrm{mM}^{-1}$ & 10-Jan & NA & 46 \\
\hline AgNPs/F-MWCNTs & $1057.3 \mu \mathrm{A} \mathrm{mM}^{-1}$ & $0.0013-1.0$ & 0.03 & 47 \\
\hline
\end{tabular}

\section{Conclusion}

In summary, this review article highlights the recent research trend in the development of electrochemical glucose biosensors. Conducting polymer PANI, which is benefitted with many attractive properties such as high electrical conductivity, favorable storage ability, and biocompatibility, plays significant role in glucose sensing systems. It provides a favorable matrix for the immobilization of glucose oxidase enzymes thus reducing the loss of enzymes loss during reaction. In addition, it can act as electron mediator and therefore facilitates the charge transfer in enzymatic or redox reaction. Derivatives of PANI have shown promising results in glucose sensing devices. A lot of literature is dedicated to the use of PANI composites for electrochemical glucose sensing. Recently, the research focus is shifted to carbon-based conducting materials such as graphene and carbon nanotubes. Significant improvement in the sensitivity and performance has been achieved for electrochemical glucose sensing using graphene and CNT based nanostructured materials. These materials are expected to be ideal models for the fabrication of stable, sensitive, reliable glucose biosensors.

\section{Acknowledgements}

The authors acknowledge the support from Higher Education Commission Pakistan for financial support.

\section{Conflict of interest}

The author declares no conflict of interest.

\section{References}

1. National diabetes data group. Classification and diagnosis of diabetes mellitus and other categories of glucose intolerance. Diabetes. 1979;28(12):1039-1057.

2. Olokoba AB, Obateru OA, Olokoba LB. Type 2 Diabetes mellitus: A review of current trends. Oman Med J. 2012;27(4):269-273.

3. WHO. Global report on diabetes; 2016.

4. Witkowska NE, Kundys M, Jeleń PS, et al. Electrochemical glucose sensing: is there still room for improvement? Analytical Chemistry. 2016;88(23):11271-11282.

5. Tian K, Prestgard M, Tiwari A. A review of recent advances in nonenzymatic glucose sensors. Mater Sci Eng C Mater Biol Appl. 2014;41:100-118.

6. Scognamiglio V. Nanotechnology in glucose monitoring: Advances and challenges in the last 10 years. Biosens Bioelectron. 2013;47:12-25.

7. Saxl T, Khan F, Ferla M, et al. A fluorescence lifetime-based fibreoptic glucose sensor using glucose/galactose-binding protein. Analyst. 2011;136(5):968-972.

8. Steiner MS, Duerkop A, Wolfbeis OS. Optical methods for sensing glucose. Chemical Society Reviews. 2011;40(9):4805-4839.

9. Wang J, Thomas DF, Chen A. Nonenzymatic electrochemical glucose sensor based on nanoporous $\mathrm{Pt} \mathrm{Pb}$ networks. Analytical Chemistry. 2008;80(4):997-1004.

10. Park S, Park S, Jeong RA, et al. Nonenzymatic continuous glucose monitoring in human whole blood using electrified nanoporous Pt. Biosens Bioelectron. 2012;31(1):284-291.

11. Soomro RA, Akyuz OP, Ozturk R, et al. Highly sensitive non-enzymatic glucose sensing using gold nanocages as efficient electrode material. Sensors and Actuators B: Chemical.2016;233:230-236.

12. Chen C, Xie Q, Yang D, et al. Recent advances in electrochemical glucose biosensors: a review. RSC Advances. 2013;3(14):4473-4491.

13. Yang J, Tan W, Chen C, et al. Nonenzymatic glucose sensing by $\mathrm{CuO}$ nanoparticles decorated nitrogen-doped graphene aerogel. Materials Science and Engineering: C. 2017;78:210-217.

14. Lin $\mathrm{KC}$, Lin YC, Chen SM. A highly sensitive nonenzymatic glucose sensor based on multi-walled carbon nanotubes decorated with nickel and copper nanoparticles. Electrochimica Acta. 2013;96:164-72.

15. Shinohara H, Chiba T, Aizawa M. Enzyme microsensor for glucose with an electrochemically synthesized enzyme-polyaniline film. Sensors and Actuators. 1988;13:79-86. 
16. Ekinci E, Alev Karagözler A, Ersin Karagözler A. Electrochemical synthesis and sensor application of poly (1,4-diaminobenzene). Synthetic Metals. 1996;79:57-61.

17. Lau KT, De Fortescu SAL, Murphy LJ, et al. Disposable glucose sensors for flow injection analysis using substituted 1,4-benzoquinone mediators Electroanalysis. 2003;15(11):975-981.

18. Xue H, Shen Z, Li Y. Polyaniline-polyisoprene composite film based glucose biosensor with high permselectivity. Synthetic Metals. 2001; 124:345-349.

19. Xian Y, Hu Y, Liu F, et al. Glucose biosensor based on Au nanoparticlesconductive polyaniline nanocomposite. Biosens Bioelectron. 2006;21(10):1996-2000.

20. Zhao M, Wu X, Cai C (2009) Polyaniline nanofibers: Synthesis, characterization, and application to direct electron transfer of glucose oxidase. J Phys Chem 113(12): 4987-4996.

21. Wang Z, Liu S, Wu P, Cai C. Detection of glucose based on direct electron transfer reaction of glucose oxidase immobilized on highly ordered polyaniline nanotubes. Anal Chem. 2009;81(4):1638-1645.

22. $\mathrm{Xu} \mathrm{L}$, Zhu Y, Yang $\mathrm{X}$, et al. Amperometric biosensor based on carbon nanotubes coated with polyaniline/dendrimer-encapsulated $\mathrm{Pt}$ nanoparticles for glucose detection. Materials Science and Engineering. C. 2009;29(4):1306-1310.

23. Zhong $\mathrm{H}$, Yuan $\mathrm{R}$, Chai $\mathrm{Y}$, et al. In situ chemo-synthesized multiwall carbon nanotube-conductive polyaniline nanocomposites: Characterization and application for a glucose amperometric biosensor Talanta. 2011;85(1):104-111.

24. Chowdhury AD, Gangopadhyay R, De A. Highly sensitive electrochemical biosensor for glucose, DNA and protein using goldpolyaniline nanocomposites as a common matrix. Sensors and Actuators B: Chemical. 2014;190:348-356.

25. Tang W, Li L, Zeng X. A glucose biosensor based on the synergistic action of nanometer-sized $\mathrm{TiO}_{2}$ and polyaniline. Talanta. 2015;131:417423.

26. Zhu J, Liu X, Wang X, et al. Preparation of polyaniline- $\mathrm{TiO}_{2}$ nanotube composite for the development of electrochemical biosensors. Sensors and Actuators B: Chemical. 2015;221:450-457.

27. Compagnone D, Federici G, Bannister JV. A new conducting polymer glucose sensor based on polythianaphthene. Electroanalysis. 1995;7(12):1151-1155.

28. Forzani ES, Zhang H, Nagahara LA, et al. A conducting polymer nanojunction sensor for glucose detection. Nano Letters. 2004;4(9):17851788 .

29. Gerard M, Chaubey A, Malhotra BD. Application of conducting polymers to biosensors. Biosens Bioelectron. 2002;17(5):345-359.

30. Ćirić-Marjanović G. Recent advances in polyaniline research: Polymerization mechanisms, structural aspects, properties and applications. Synthetic Metals. 2013;177:1-47.

31. Pan X, Kan J, Yuan L. Polyaniline glucose oxidase biosensor prepared with template process. Sensors and Actuators B: Chemical. 2004;102:325-330.

32. Malitesta C, Palmisano F, Torsi L, et al. Glucose fast-response amperometric sensor based on glucose oxidase immobilized in an electropolymerized poly(o-phenylenediamine) film. Anal Chem. 1990;62(24):2735-2740.
33. Ramanathan K, Pandey SS, Kumar R, et al. Covalent immobilization of glucose oxidase to poly(O-amino benzoic acid) for application to glucose biosensor. J Appl Polym Sci. 2000;78(3):662-667.

34. Cooper JC, Hall EAH. Catalytic reduction of benzoquinone at polyaniline and polyaniline/enzyme films. Electroanalysis. 1993;5-6:385-397.

35. Gopalan AI, Lee KP, Ragupathy D, et al. An electrochemical glucose biosensor exploiting a polyaniline grafted multiwalled carbon nanotube/ perfluorosulfonate ionomer-silica nanocomposite. Biomaterials. 2009;30(30):5999-6005.

36. Granot E, Katz E, Basnar B, et al. Enhanced bioelectrocatalysis using Au-nanoparticle/polyaniline hybrid systems in thin films and microstructured rods assembled on electrodes. Chemistry of Materials. 2005; 17(18):4600-4609.

37. Zhou H, Chen H, Luo S, et al. Glucose biosensor based on platinum microparticles dispersed in nano-fibrous polyaniline. Biosens Bioelectron. 2005;20(7):1305-1311.

38. Hossain MF, Park JY. Plain to point network reduced graphene oxide activated carbon composites decorated with platinum nanoparticles for urine glucose detection. Sci Rep. 2016;6:21009.

39. Hsu YW, Hsu TK, Sun $\mathrm{CH}$, et al. Synthesis of $\mathrm{CuO} /$ graphene nanocomposites for nonenzymatic electrochemical glucose biosensor applications. Electrochimica Acta. 2012;82:152-157.

40. Tehrani F, Bavarian B. Facile and scalable disposable sensor based on laser engraved graphene for electrochemical detection of glucose. $\mathrm{Sci}$ Rep. 2016;6:27975.

41. Zhao Y, Li W, Pan L, et al. ZnO-nanorods/graphene heterostructure: a direct electron transfer glucose biosensor. Sci Rep. 2016;6:32327.

42. Zeng G, Li W, Ci S, et al. Highly dispersed NiO nanoparticle decorating graphene nanosheets for non-enzymatic glucose sensor and biofuel cell. Sci Rep. 2016;6:36454.

43. Ju L, Wu J, Lu B, et al. Non-enzymatic amperometric glucose sensor based on copper nanowires decorated reduced graphene oxide. Electroanalysis. 2016;28(10):2543-2551.

44. Pang X, Imin P, Zhitomirsky I, et al. Conjugated polyelectrolyte complexes with single-walled carbon nanotubes for amperometric detection of glucose with inherent anti-interference properties. J Mater Chem. 2012;22:9147-9154.

45. Tsai TW, Heckert G, Neves LF, et al. Adsorption of glucose oxidase onto single-walled carbon nanotubes and its application in layer-by-layer biosensors. Anal Chem. 2009;81(19):7917-7925.

46. Gomathi P, Min K, Kwan P, et al. Multiwalled carbon nanotubes grafted chitosan nanobiocomposite: A prosperous functional nanomaterials for glucose biosensor application. Sensors and Actuators B. 2011;155:897902.

47. Ensafi AA, Zandi-Atashbar N, Rezaei B, et al. Non-enzymatic glucose electrochemical sensor based on silver nanoparticle decorated organic functionalized multiwall carbon nanotubes. RSC Advances. 2016;6:60926-60932. 